\title{
Synthesis of Tetrahydrocarbazole Derivatives as Potent $\beta_{3}$-Adrenoceptor Agonists
}

\author{
Jae Du Ha, Seung Kyu Kang, Hyae-Gyeong Cheon, and Joong-Kwon Choi" \\ Medicinal Science Division, Korea Research Institute of Chemical Technolog, Daejeon 305-600, Korea \\ Received July 27, 2004
}

\begin{abstract}
A series of 2-(3-chlorophenỵl)-2-hỵdroxỵethỵlamine derivatives containing a tetrahydrocarbazole linker were prepared and evaluated for their $\beta_{5}$-adrenoceptor agonistic activity. Several compounds showed potency comparable to CL-316243.
\end{abstract}

Key Words : $\beta_{3}$-Adrenoceptor, Tetrahydrocarbazole. Arylethanolanine. Antiobesty

\section{Introduction}

As a subclass of $\beta$-adrenoceptors, ${ }^{1} \beta_{5}$-adrenoceptor $\left(\beta_{3}\right.$ $A R)^{2}$ is found on the cell surface of both white and brown adipocytes and mediates various metabolic processes such as lipolysis and thermogenesis. ${ }^{3}$ Activation of human $\beta_{3}-\mathrm{AR}$ results in an increase of $\mathrm{c}$-AMP level in adipocytes, leading to an elevation of metabolic rate. Therefore. discovery of a human $\beta_{5}$-AR agonist would be an attractive approach to the treatment of human disease states. such as obesity and type II diabetes. ${ }^{4}$ Although many early $\beta_{3}$-AR agonists such as BRL 37344, CL-316243. ${ }^{5}$ AJ 9677, ${ }^{7}$ and SR58611 ${ }^{8}$ were tested in clinical trials, these $\beta_{5}$-AR agonists suffered a poor potency or substantial $\beta_{1}-A R$ and $\beta_{-}-A R$ mediated side effects in human. Recently a number of laboratories have been developing new classes of $\beta_{3}$-AR agonists, such as Solabegron ${ }^{9}$ and N-5984. ${ }^{16}$ having much higher potency and less side effects than the early $\beta_{5}$-AR agonists. However. those compounds still need improvement, and new $\beta_{3}-\mathrm{AR}$ agonists as viable antiobestic or antidiabetic agents with improved potency are pursued.

Most of $\beta_{5}$-AR agonists tested in clinical trials possess the 2-(3-chlorophenyl)-2-hydroxyethylamino group in the lefthand side and a carbosylic acid or its isostere in the righthand side, which is considered to be critical for showing $\beta_{5}$ AR agonistic activity, and a variety of aromatic ring systems. ${ }^{11}$ such as phenyl, pyridine, ${ }^{12}$ indole. tetrahydronaphthalene, and benzodioxine. were used as a linker of $\beta_{i}$-AR agonists. With considering those. we decided to test a tetrahydrocarbazole moiety as a linker for a new potent $\beta_{5}$-AR agonist. In this paper we describe the synthesis and structure-activity study of a variety of 2-(tetrahydrocarbazol-3-ylamino)-1-(3chlorophenyl)ethanol derivatives, leading to the discovery of a new and potent $\beta_{s}$-AR agonist.

\section{Chemistry}

The general synthetic route to tetrahydrocarbazole deriva-<smiles>[M]C(Cc1ccc2c(c1)OC(C(N)=O)(C(N)=O)O2)NC[C@H](O)c1cccc(Cl)c1</smiles>

CL-316243<smiles>CCOC(=O)COc1ccc2c(c1)C[C@@H](NC[C@H](O)c1cccc(Cl)c1)CC2</smiles>

SR-58611A<smiles>CC(Cc1ccc2c(c1)OC[C@H](C(=O)O)O2)NC[C@H](O)c1cccc(Cl)c1</smiles>

N-5984<smiles>C[C@H](Cc1c[nH]c2c(OCC(=O)O)cccc12)NC[C@@H](O)c1cccc(Cl)c1</smiles>

AJ-9677<smiles>[R]c1ccc2[nH]c3c(c2c1)CC(NC[C@H](O)c1cccc(Cl)c1)CC3</smiles>

1

Figure 1

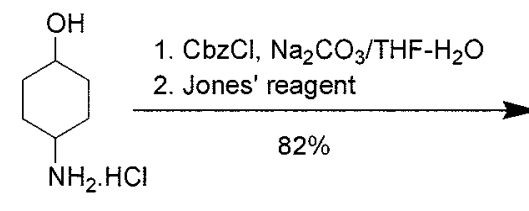

2

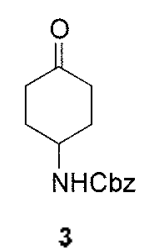

3

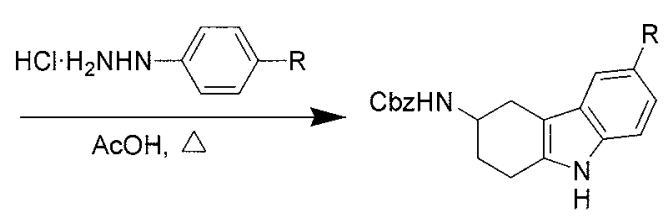

Scheme 1 4a, $\mathrm{R}=\mathrm{OMe}(72 \%)$

4b, $\mathrm{R}=\mathrm{CO}_{2} \mathrm{H}(53 \%)$

4c. $\mathrm{R}=\mathrm{CH}_{2} \mathrm{CO}_{2} \mathrm{Me}(39 \%)$

4d, $\mathrm{R}=\mathrm{CO}_{2} \mathrm{Et}(50 \%)$

4e, $R=F(62 \%)$

$4 f, R=H(72 \%)$

4g. $\mathrm{R}=\mathrm{Br}(69 \%)$ 


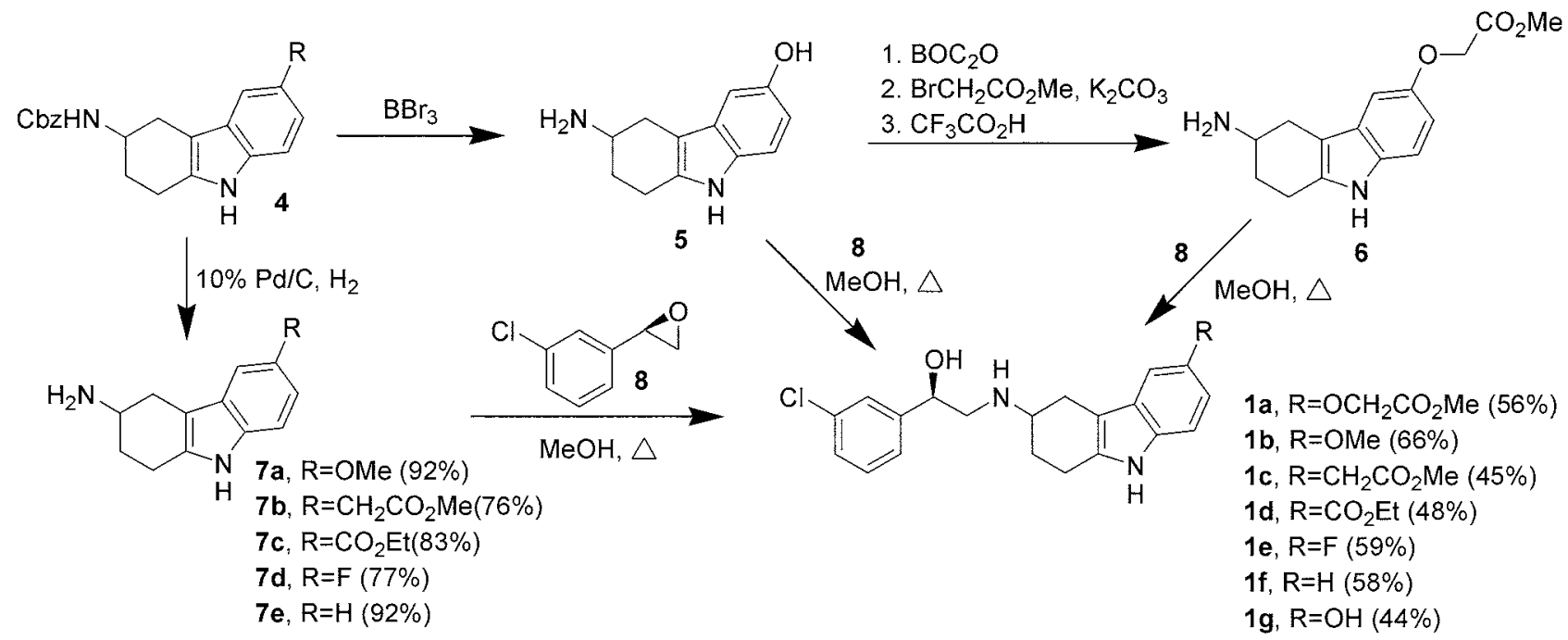

Scheme 2
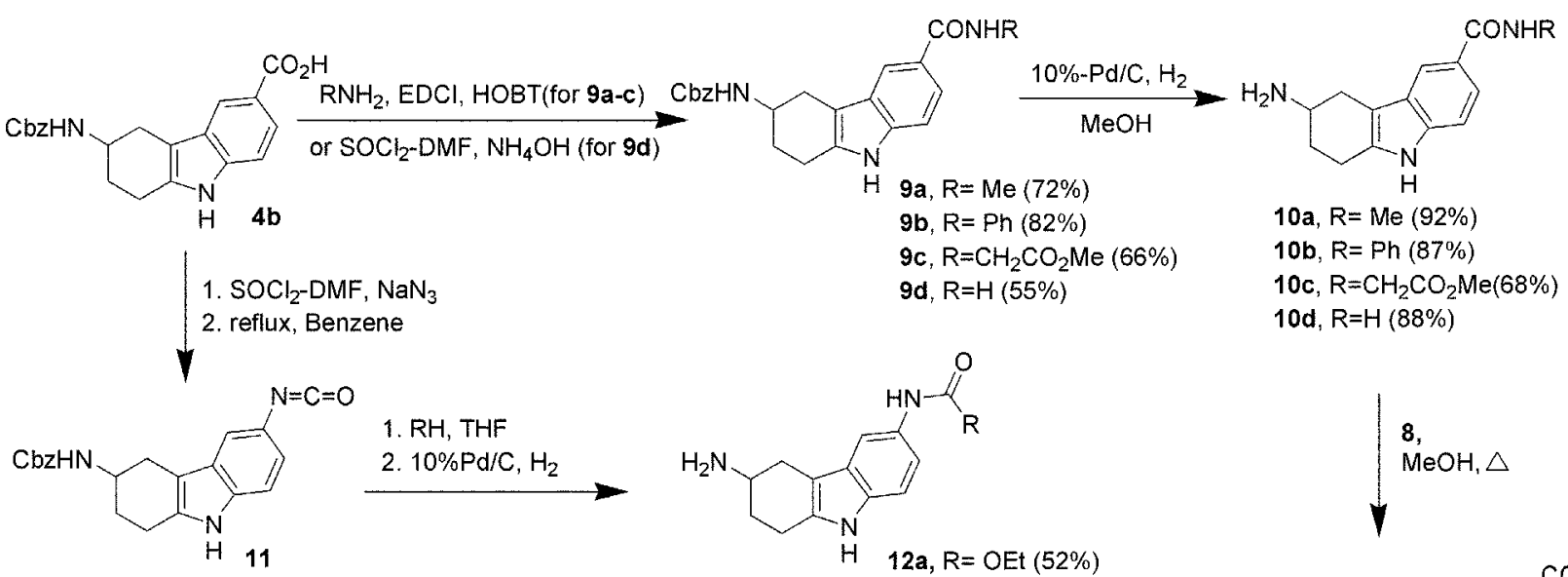

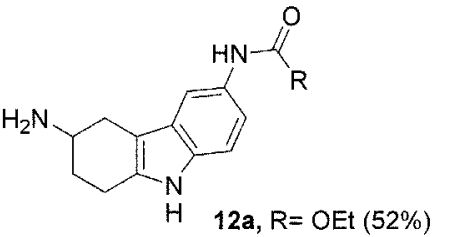

8 , $\mathrm{MeOH}, \triangle$ 12a, $R=$ OEt $(52 \%)$ $42 \%\left\{\begin{array}{l}\text { 1. } 2 \mathrm{~N}-\mathrm{HCl}, \\ 2 . \mathrm{MeSO}_{2} \mathrm{Cl}_{1} \mathrm{Et}_{3} \mathrm{~N} \\ 3.10 \% \mathrm{Pd} / \mathrm{C}, \mathrm{H}_{2}\end{array}\right.$

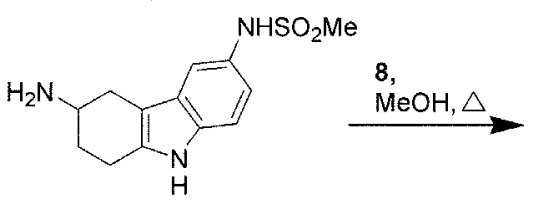

13

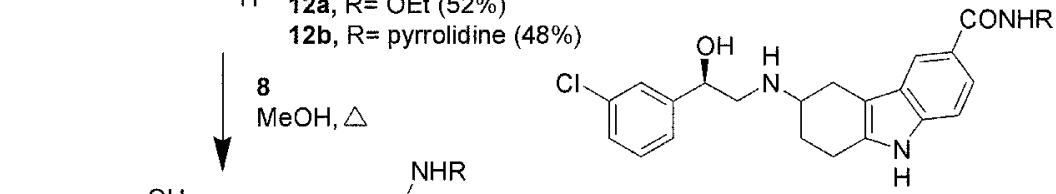

1h, $\mathrm{R}=\mathrm{Me}(42 \%)$ 1i, $\mathrm{R}=\mathrm{Ph}(37 \%)$

1j, $\mathrm{R}=\mathrm{CH}_{2} \mathrm{CO}_{2} \mathrm{Me}(38 \%)$ $1 k, \mathrm{R}=\mathrm{H}(58 \%)$
1I, $\mathrm{R}=\mathrm{CO}_{2} \mathrm{Et}(68 \%)$ $1 \mathrm{~m}, \mathrm{R}=\mathrm{CO}$-pyrrolidine $(48 \%)$ 1n, $\mathrm{R}=\mathrm{SO}_{2} \mathrm{Me}(59 \%)$

Scheme 3

tives is shown in Scheme 1. The 3-(benzyloxycarbonylamino)-1.2.3.4-tetrahydrocarbazole derivatives 4 were prepared by following similar methods described in literatures. $^{13}$

The synthesis began with a conmercially available 4aminocyclohexanol 2. which was treated with $\mathrm{CbzCl}$ and $\mathrm{Na}_{2} \mathrm{CO}_{3}$. followed by oxidation with Jones reagent to give the cyclohexanone 3 . Fisher cyclization of the cyclohexanone 3 with various aryl hỵdrazines in refluxing acetic acid gave the tetrahy'drocarbazole derivatives $\mathbf{4 a - g}$ (Scheme 1)

Synthesis of arylethanolamines 1a-g was achieved as described in Scheme 2. Cleavage of the $\mathrm{Cbz}$ group and methyl ether using $\mathrm{BBr}_{3}$ provided the corresponding 6aminotetrahy'drocarbazol-3-ol (5). Then. amino group was protected with Boc group followed by alkylation of phenol with methyl bromoacetate and subsequent deprotection of Boc amino group using $\mathrm{CF}_{3} \mathrm{CO}_{2} \mathrm{H}$ to furnish aminotetrahydrocarbazole 6. A catalytic hydrogenolysis of $4 a$ and $\mathfrak{t} \mathbf{c}-\mathbf{f}$ using $\mathrm{Pd} / \mathrm{C}$ provided the aminocarbazole derivatives 7a-e. For the synthesis of arylethanolamines 1 a-g. 3-aminotetrahydrocarbazole derivatives 5. 6. and 7a-e were treated with an optically pure $(R)$-3-chlorostry rene oxide 8 in 
<smiles>CC(=O)NC1CCc2[nH]c3ccc(Br)cc3c2-c2c1[nH]c1ccc(C(C)(C)C)cc21</smiles>

Scheme 4

$\mathrm{MeOH}$.

The arylethanolamines $\mathbf{~ h}-\mathbf{n}$ were prepared as outlined in Scheme 3. Coupling of the carboxylic acid $4 \mathbf{b}$ with various amines using EDCI and HOBT to afford the amides 9a-c. followed by a catalytic hydrogenolysis furnished aminotetrahydrocarbazole 10a-c. The carboxamide $9 \mathrm{~d}$ was readily synthesized by the activation of the carboxylic acid using SOCl-DMF followed by addition of ammonia/water.

For the synthesis of 12a-b and 13, the carboxylic acid $4 \mathbf{b}$ was subjected to Curtis rearrangement condition using SOCl-DMF adduct as activating agent followed by heating in benzene to provide the isocyanate 11. Nucleophilic addition of EtOH or pyrrolidine to isocyanate $\mathbf{1 1}$ by heating in THF and a subsequent hydrogenolysis afforded the aminotetrahydrocarbazoles 12a-b. Hydrolysis of the isocyanate 11 in $2 \mathrm{~N}$-HCl afforded the 6-aminotetrahydrocarbazole. which was treated with methansulfonyl chloride followed by catalytic hydrogenolysis to give the sulfonamide 13. The arylethanolamines $1 \mathrm{~h}-\mathrm{n}$ were prepared by following the same method as described in Scheme 2 .

The arylethanolamine 10 was prepared according to Scheme 4 . Heck reaction of $4 \mathrm{~g}$ with methyl acrylate using $\mathrm{Pd}(\mathrm{OAc})$ a afforded the tetrahydrocarbazol acrylic ester 14. Catalytic hydrogenation and hydrogenolysis followed by coupling with 8 afforded the ary lethanolamine 10

\section{Screening Results}

The arylethanolamines were tested for their in vitro activity by using cell membrane expressing human $\beta_{3}$-AR $\left.(\mathrm{RB}-\mathrm{HBETA})_{3}\right)^{14}$ and the results are summarized in Table 1. CL-316243 was also included as a reference. Due to the difference of assay conditions. CL-316243 exhibited a relatively lower agonistic activity than that of previously reported data. ${ }^{6}$

As shown in Figure 1. the carboxylic acid or its ester functionalities in the right-hand side of $\beta_{3}-\mathrm{AR}$ agonist is important for maintaining $\beta_{3}$-AR agonist activity and desirable physical properties. As expected. introduction of the methoxycarbony lmethoxy' group $\left(\mathrm{R}=\mathrm{OCH}_{2} \mathrm{CO}_{2} \mathrm{Me}\right.$. 1a) at C-6 position of tetrahy'drcarbazole displayed comparable in vitro activity $\left(\mathrm{IC}_{s i j}=1.2 \mu \mathrm{M}\right)$ to that of $\mathrm{CL}-316243$ $\left(\mathrm{IC}_{\Sigma \mathrm{si}}=1.17 \mu \mathrm{M}\right)$. A simple tetrahydrocarbazole 1e without any substituent was about 5 -fold less potent compared with 1a. The compounds $1 \mathrm{~b}$. $1 \mathrm{~d}$. and $\mathbf{1 f}$ with non-carbosylate functionalities were quite active. especially: the fluoro substituted compound if was even more potent $\left(\mathrm{IC}_{S_{i j}}=0.79\right.$
Table 1. In vitro Activity for Tetrahydrocarbazole Derivatives

\begin{tabular}{|c|c|c|c|}
\hline Compl & $\mathrm{R}$ & $\mathrm{IC}_{50}(\mu \mathrm{M})$ & $\mathrm{Ki}(\mu \mathrm{M})$ \\
\hline 1a & $\mathrm{OCH}_{2} \mathrm{CO}_{2} \mathrm{Me}$ & 1.20 & 0.64 \\
\hline 1b & $\mathrm{OMe}$ & 1.28 & 0.55 \\
\hline lc & $\mathrm{CH}_{2} \mathrm{CO}_{2} \mathrm{Me}$ & 2.85 & 1.22 \\
\hline 1d & F & 0.79 & 0.34 \\
\hline le & $\mathrm{H}$ & 5.10 & 2.19 \\
\hline If & $\mathrm{OH}$ & 1.37 & 0.58 \\
\hline $\lg$ & CONHMe & 2.58 & 1.10 \\
\hline lh & CONHPh & 0.19 & 0.09 \\
\hline li & $\mathrm{CONHCH}_{2} \mathrm{CO}_{2} \mathrm{Me}$ & 0.40 & 0.17 \\
\hline $\mathbf{1 j}$ & $\mathrm{CONH}_{2}$ & 0.64 & 0.27 \\
\hline $1 k$ & $\mathrm{CO}_{2} \mathrm{Et}$ & 0.21 & 0.09 \\
\hline 11 & $\mathrm{NHCO}_{2} \mathrm{Et}$ & 0.81 & 0.35 \\
\hline $1 \mathrm{~m}$ & NHCOpyrrolidine & 24.93 & 10.69 \\
\hline ln & $\mathrm{NHSO}_{2} \mathrm{Me}$ & 2.12 & 0.91 \\
\hline 10 & $\mathrm{CH}_{2} \mathrm{CH}_{2} \mathrm{CO}_{2} \mathrm{Me}$ & 6.68 & 2.86 \\
\hline CL-3162+3 & & 1.17 & 0.62 \\
\hline
\end{tabular}

$\mu \mathrm{M})$. Although the amide derivatives are known to be moderate isostere of carboxylic acid. we synthesized a variety of amide derivatives for evaluation. While the $\mathrm{N}$ methylamide $1 \mathrm{~g}$ showed poor activity. the activities of the amide $\mathbf{l h} . \mathbf{l i}$. and $1 \mathbf{k}$ were significantly increased. To our delight. phenyl amide $1 \mathrm{~h}$ was the most potent compound synthesized. which showed about 6-fold higher potency compared to that of CL-316243. In terms of tether length modifications. comparison of the activities of compounds $1 \mathrm{c} .1 \mathrm{k}$, and 10 indicated that increasing length to methylene or ethylene led to diminished activity compared to that of the directly attached carboxylate $1 \mathbf{k}\left(\mathrm{IC}_{s i j}=0.21 \mu \mathrm{M}\right)$. We also sy'nthesized a series of tetrahydrocarbazolyl anine derivatives. such as carbamate (11), urea $(\mathbf{1 m})$. and sulfonamide (1n). which all resulted in decreased activities.

In addition. all compounds were tested for their plasma glucose lowering activity in obese hyperglycemic $a b a b$ mice. Among them. $5 \mathrm{mg} / \mathrm{kg} / \mathrm{day}$ of $1 \mathrm{n}$ significantly reduced plasma glucose concentrations in 3 days from $231 \mathrm{mg} / \mathrm{dl}$ to $176 \mathrm{mg} / \mathrm{dl}$. which was similar to that of CL-316243 (233 $\mathrm{mg} / \mathrm{dl}$ to $152 \mathrm{mg} / \mathrm{dl}){ }^{15}$ 


\section{Conclusions}

The syinthesis and SAR studies of substituted tetrahỵdrocarbazole derivatives have been discussed. The tetrahydrocarbazoles $\mathbf{1 h}$ and $\mathbf{1 k}$ showed about $\mathbf{5}$-fold potency in vitro $\beta_{3}$-AR activity compared with CL-316243. A further pharmacological evaluation of these compounds is in progress

\section{Experimental Sections}

(4-Oxocyclohexyl)carbamic acid benzyl ester (3). To a suspension of 4-aminocyclohexanol hydrochloride $(5 \mathrm{~g}$. $32.97 \mathrm{mmol})$ and $\mathrm{Na}_{2} \mathrm{CO}_{3}(7 \mathrm{~g} .66 \mathrm{mmol})$ in $\mathrm{THF}-\mathrm{H}_{2} \mathrm{O}(4: 1$. $100 \mathrm{~mL})$ was dropwise added benzyl chloroformate $(5.2 \mathrm{~mL}$. $36.27 \mathrm{mmol})$ in $\mathrm{THF}(5 \mathrm{~mL})$ at $0^{\circ} \mathrm{C}$ and the reaction mixture was stirred for $2 \mathrm{~h}$ at $0^{\circ} \mathrm{C}$. The mixture was diluted with EtOAc and the organic layer was washed with water and brine dried over $\mathrm{MgSO}_{4}$, and concentrated to give a cnude (4-hydroxycyclohexyl)carbamic acid benzyl ester $(8.2 \mathrm{~g}$ ). which was subjected to the next reaction without further purification

To a solution of a crude (4-hydroxycyclohexyl)carbamic acid benzyl ester in acetone (100 $\mathrm{mL}$ ) was added Jones' reagent $(5.2 \mathrm{~mL}, 41.6 \mathrm{mmol})$ at $0{ }^{\circ} \mathrm{C}$ and the reaction mixture was stirred for $30 \mathrm{~min}$. then quenched by addition of isopropyl alcohol (4 $\mathrm{mL}$ ). After stirring for $5 \mathrm{~min}$. the mixture was filtered. and washed with acetone. The filtrate was concentrated and partitioned between water and EtOAc. The organic layer was dried over $\mathrm{MgSO}_{4}$. concentrated and purified by silica gel column chromatography (Hex: EtOAc $=3: 1$ ) to afford the cyclohexanone $3(6.7 \mathrm{~g} .82 \%)$ : ${ }^{l} \mathrm{H}$ NMR $\left(200 \mathrm{MHz}, \mathrm{CDCl}_{3}\right) \delta 7.37-7.30(\mathrm{~m}, 5 \mathrm{H}), 5.04$ (s. 2H). 3.84 (m. 1H). $2.40(\mathrm{~m}, 2 \mathrm{H}), 2.27(\mathrm{~m}, 2 \mathrm{H}) .1 .99(\mathrm{~m} .2 \mathrm{H}) .1 .68(\mathrm{~m}$. 2H).

(6-Methoxy-2,3,4,9-tetrahydro-1 $H$-carbazol-3-yl)carbamic acid benzyl etster (4a). A solution of 4-methoxyphenyl hydrazine hydrochloride (1.94 g. $11.13 \mathrm{mmol}$ ). sodium acetate $(1.25 \mathrm{~g} .15 .1 \mathrm{mmol})$, and cyclohexanone $6(2.5 \mathrm{~g}$. $10.12 \mathrm{mmol}$ ) in acetic acid $(50 \mathrm{~mL})$ was heated for $20 \mathrm{~h}$ at reflux. The solvent was removed in vacuo and the residue was partitioned between water and EtOAc. The organic layer was dried. concentrated. and purified by column chromatography ( $\mathrm{Hex}: \mathrm{EtOAc}=4: 1$ ) to give the 6-methoxytetrahydrocarbazole 4a $(2.55 \mathrm{~g}, 72 \%)$. ${ }^{\mathrm{l}} \mathrm{H}$ NMR $(200$ $\left.\mathrm{MHz} \mathrm{CDCl}_{3}\right) \delta 7.77$ (brs. $\left.1 \mathrm{H}\right) .7 .53-7.25(\mathrm{~m} .7 \mathrm{H}), 7.16(\mathrm{~d} . J$ $=8.0 \mathrm{~Hz}, 1 \mathrm{H}) \cdot 6.88(\mathrm{~d} J=2.4 \mathrm{~Hz}, 1 \mathrm{H}), 6.80(\mathrm{dd} J=8.0 .2 .4$ $\mathrm{Hz}, 1 \mathrm{H}), 5.12(\mathrm{~s}, 2 \mathrm{H}), 4.94(\mathrm{~d} . J=7.6 \mathrm{~Hz}, 1 \mathrm{H}), 4.20(\mathrm{~m}, \mathrm{lH})$. 3.84 (s. $3 \mathrm{H}$ ). 3.10 (dd. $J=15.6 .5 .4 \mathrm{~Hz}, 1 \mathrm{H}$ ). $2.80(\mathrm{~m} .2 \mathrm{H})$. 2.63 (dd. $J=15.4 .6 .8 \mathrm{~Hz}, 1 \mathrm{H}) .2 .09(\mathrm{~m} .2 \mathrm{H})$.

6-Benzyloxycarbonylamino-6,7,8,9-tetrahydro-5 $H$-carbazole-3-carboxylic acid (4b). 'H NMR (300 MHz, DMSOd 6 ) $\delta 12.2$ (brs. $1 \mathrm{H}) .9 .72$ (s. $1 \mathrm{H}$ ). 8.58 (s. $1 \mathrm{H}$ ). 7.63 (dd. $J=$ $8.7 .1 .2 \mathrm{~Hz}, 1 \mathrm{H}) 7.38-7.32(\mathrm{~m}, 6 \mathrm{H}) .7 .28(\mathrm{~d} . J=8.7 \mathrm{~Hz}, 1 \mathrm{H})$. 5.05 (s. 2H). 3.84 (m. 1H). 2.97 (dd $J=15.0 .5 .1 \mathrm{~Hz} .1 \mathrm{H}$ ). $2.81(\mathrm{~m} .2 \mathrm{H}) .2 .57(\mathrm{dd} . J=15.0 .6 .7 \mathrm{~Hz}, 1 \mathrm{H}) .2 .05(\mathrm{~m} . \mathrm{lH})$. $1.80(\mathrm{~m}, 1 \mathrm{H})$
(6-Benzyloxycarbonylamino-6,7,8,9-tetrahydro-5 $\mathrm{H}$ carbazol-3-yl)acetic acid methyl ester (4c). ${ }^{\mathrm{l}} \mathrm{H}$ NMR $(200$ $\left.\mathrm{MHz}, \mathrm{CDCl}_{2}\right) \delta 7.77$ (brs. $\left.1 \mathrm{H}\right), 7.35-7.30(\mathrm{~m}, 6 \mathrm{H}) .7 .21$ (d. J $=8.1 \mathrm{~Hz}, 1 \mathrm{H}) .7 .04($ dd. $J=8.1,1.6 \mathrm{~Hz}, 1 \mathrm{H}) .5 .11(\mathrm{~s} .2 \mathrm{H})$. 4.92 (m. 1H), 4.17 (m. 1H). 3.69 (s. 2H). 3.67 (s. 3H). 3.07 (dd. $J=15.4,5.4 \mathrm{~Hz}, 1 \mathrm{H}$ ), 2.79 (n. $2 \mathrm{H}$ ). 2.59 (dd $J=15.4$. $6.7 \mathrm{~Hz}, 1 \mathrm{H}), 2.00(\mathrm{~m} .2 \mathrm{H})$ : MS (me). $392\left(\mathrm{M}^{-} .11\right), 241$ (100). $215(17), 180(41), 156(37), 91(53)$.

6-Benzyloxycarbonyl-6,7,8,9-tetrahydro-5 $\mathrm{H}$-carbazole3-carboxylic acid ethyl ester (4d). ' $\mathrm{H}$ NMR (200 MHz. $\left.\mathrm{CDCl}_{3}\right) \delta 8.18(\mathrm{dd} . J=1.6,0.6 \mathrm{~Hz}, 1 \mathrm{H}$ ) .8 .07 (brs. $1 \mathrm{H}) .7 .85$ (dd. $J=8.5,1.6 \mathrm{~Hz}, 1 \mathrm{H}), 7.26($ dd $J=8.5,0.6 \mathrm{~Hz}, 1 \mathrm{H})$. $7.35-7.33(\mathrm{~m}, 5 \mathrm{H}), 5.11$ (s. $2 \mathrm{H}), 4.94$ (br d. $1 \mathrm{H}), 4.38$ (q. $J=$ $7.2 \mathrm{~Hz} .2 \mathrm{H}$ ). 4.17 (m. 1H). 3.13 (dd. $J=15.6 .5 .4 \mathrm{~Hz}, 1 \mathrm{H})$. $2.81(\mathrm{~m}, 2 \mathrm{H}), 2.65(\mathrm{dd} J=15.6,6.8 \mathrm{~Hz}, 1 \mathrm{H}), 2.05(\mathrm{~m}, 2 \mathrm{H})$, $1.41(\mathrm{t}, J=7.2 \mathrm{~Hz}, 3 \mathrm{H})$ : MS (me), $392\left(\mathrm{M}^{+}, 11\right), 347(8)$. 241 (100). 215 (13). 168 (16). 91 (21).

(6-Fluoro-2,3,4,9-tetrahydro- $1 \boldsymbol{H}$-carbzaol-3-yl)carbamic acid benzyl ester (4e). ${ }^{1} \mathrm{H}$ NMR (200 MHz. CDCl $\left.{ }_{2}\right) \delta 7.82$ (br s. $1 \mathrm{H}$ ) $, 7.37-7.34(\mathrm{~m}, 5 \mathrm{H}), 7.15(\mathrm{dd} . J=8.7 .4 .4 \mathrm{~Hz}, 1 \mathrm{H}$ ). 7.04 (dd $J=9.3 .2 .4 \mathrm{~Hz}, 1 \mathrm{H}), 6.85(\mathrm{~m}, 1 \mathrm{H}) .5 .11(\mathrm{~s} .2 \mathrm{H})$, $4.94(\mathrm{~m}, 1 \mathrm{H}), 4.16(\mathrm{~m}, 1 \mathrm{H}), 3.03(\mathrm{dd} . J=15.2 .4 .8 \mathrm{~Hz} .1 \mathrm{H})$. 2.81-2.75 (m. 2H). 2.55 (dd $J=15.4,6.9 \mathrm{~Hz}, 1 \mathrm{H}), 2.00(\mathrm{~m}$. 2H): MS (me). $338\left(\mathrm{M}^{+} .1\right) .186(100) .161(86) .91(82)$.

(2,3,4,9-Tetrahydro-1 $\boldsymbol{H}$-carbazol-3-yl)carbamic acid benzyl ester (4f). ${ }^{1} \mathrm{H}$ NMR $\left(200 \mathrm{MHz}, \mathrm{CDCl}_{2}\right) \delta 7.76$ (brs. $1 \mathrm{H}) .7 .44-7.27(\mathrm{~m}, 5 \mathrm{H}), 7.19-7.06(\mathrm{~m}, 2 \mathrm{H}), 5.11$ (s. 2H). $4.92(\mathrm{~m}, 1 \mathrm{H}), 4.20(\mathrm{~m}, 1 \mathrm{H}), 3.09(\mathrm{dd} . J=15.6 .5 .4 \mathrm{~Hz} .1 \mathrm{H})$. $2.80(\mathrm{~m}, 2 \mathrm{H}), 2.62(\mathrm{dd} . J=15.6,6.6 \mathrm{~Hz}, 1 \mathrm{H}), 2.19-1.85(\mathrm{~m}$ 2H): MS (me). $364\left(\mathrm{M}^{+} .2\right), 256$ (3). 213 (37). 168 (25). 91 (100).

(6-Bromo-2,3,4,9-tetrahydro-1 $H$-carbzalol-3-yl)carbamic acid benzyl ester (4g). ${ }^{1} \mathrm{H}$ NMR $(200 \mathrm{MHz}$. DMSO-d 6 $\left.\mathrm{CDCl}_{3}\right) \delta 10.5$ (brs, $\left.1 \mathrm{H}\right), 7.45-7.06(\mathrm{~m}, 8 \mathrm{H}) .6 .38(\mathrm{~m}, \mathrm{lH})$. $5.09(\mathrm{~s} .2 \mathrm{H}) .4 .02(\mathrm{~m}, 1 \mathrm{H}) .3 .00(\mathrm{~m} .1 \mathrm{H}) .2 .84(\mathrm{~m} .2 \mathrm{H}) .2 .58$ (m, 1H). $2.10(\mathrm{~m}, 1 \mathrm{H}) .1 .95(\mathrm{~m}, 1 \mathrm{H})$ : MS (m e) $398\left(\mathrm{M}^{+}-1\right.$. 15). $247(100), 221(22), 167(60) .91(61)$.

6-Amino-6,7,8,9-tetrahydro-5 $H$-carbazol-3-ol (5). To a solution of (6-methoxy-2.3.4.9-tetrahydro- $1 \mathrm{H}$-carbazol-3yl)carbamic acid benzyl ester (1.2 g. $3.42 \mathrm{mmol}$ ) in $\mathrm{CH}_{2} \mathrm{Cl}_{2}$ (30 $\mathrm{mL}$ ) was added $1 \mathrm{M}-\mathrm{BBr}_{2} / \mathrm{CH}_{2} \mathrm{Cl}_{2}(8.6 \mathrm{~mL} .8 .6 \mathrm{mmol})$ at $0^{\circ} \mathrm{C}$. The mixture was stirred for $6 \mathrm{~h}$ at room temperature. then quenched with addition of $s a t-\mathrm{NaHCO}_{3}$ solution at 0 ${ }^{\circ} \mathrm{C}$. The mixture was basified with addition of $1 \mathrm{~N}-\mathrm{NaOH}$ solution and extracted with EtOAc $(3 \times 20 \mathrm{~mL})$. which was dried over $\mathrm{Na}_{2} \mathrm{SO}_{4}$. and concentrated to give the aminocarbazole $5(0.36 \mathrm{~g} .52 \%)$ : ${ }^{1} \mathrm{H}$ NMR (200 MHz, CD $\left.30 \mathrm{OD}\right) \delta$ 7.04 (d. $J=8.4 \mathrm{~Hz}, 1 \mathrm{H}), 6.73$ (d. $J=2.4 \mathrm{~Hz} .1 \mathrm{H}), 6.55$ (dd. $J$ $=8.4 .2 .4 \mathrm{~Hz}, 1 \mathrm{H}), 3.24(\mathrm{~m}, 1 \mathrm{H}) .3 .15(\mathrm{~m}, 1 \mathrm{H}) .2 .90(\mathrm{dd}, J=$ $15.0 .5 .4 \mathrm{~Hz}, 1 \mathrm{H}), 2.78(\mathrm{~m} .2 \mathrm{H}) .2 .32(J=15.0 .8 .4 \mathrm{~Hz}, 1 \mathrm{H})$. $2.01(\mathrm{n} .1 \mathrm{H}) .1 .76(\mathrm{~m}, 1 \mathrm{H})$ : MS (me). $202\left(\mathrm{M}^{-}, 44\right) .184$ (10). $159(100), 130(6) .77(5)$.

(6-Amino-6,7,8,9-tetrahydro-5H-carbazol-3-yloxy)acetic acid methyl ester (6). To a solution of $5(0.28 \mathrm{~g} .1 .40 \mathrm{mmol})$ in $\mathrm{THF}-\mathrm{H}_{2} \mathrm{O}(4: 1.25 \mathrm{~mL})$ was added $\mathrm{Na}_{2} \mathrm{CO}_{3}(0.44 \mathrm{~g} .4 .2$ mmol) and (BOC) $)_{2} \mathrm{O}(0.63 \mathrm{~g} .2 .8 \mathrm{mmol})$ at $0^{\circ} \mathrm{C}$ and the misture was stirred for $1 \mathrm{~h}$ at $0^{\circ} \mathrm{C}$. The solution was diluted 
with EtOAc and the organic layer was separated washed with brine dried. concentrated and purified with column chromatography (Hex: EtOAc $=4: 1$ ) to give the $\mathrm{BOC}$ amino carbazole: ' $\mathrm{H}$ NMR (200 $\left.\mathrm{MHz} . \mathrm{CDCl}_{3}\right) \delta 7.75$ (brs. $1 \mathrm{H}) .7 .08(\mathrm{~d} . J=8.6 \mathrm{~Hz}, 1 \mathrm{H}) .7 .79$ (brs. $1 \mathrm{H}) .6 .68(\mathrm{dd} . J=$ $8.4 .2 .6 \mathrm{~Hz} .1 \mathrm{H}) .5 .63(\mathrm{~m} .1 \mathrm{H}) .4 .76(\mathrm{~m}, 1 \mathrm{H}) .2 .93$ (dd. $J=$ $15.6 .5 .0 \mathrm{~Hz}, 1 \mathrm{H}), 2.74(\mathrm{~m}, 2 \mathrm{H}), 2.43(J=15.6 .7 .0 \mathrm{~Hz}, \mathrm{lH})$. 1.82 (m. 2H): MS (me). $302\left(\mathrm{M}^{+}, 100\right), 245$ (29). 229 (38). 184 (78). 159 (94) 57 (46). To a solution of the BOC amino carbazole $(0.23 \mathrm{~g} .0 .75 \mathrm{mmol})$ in acetone $(10 \mathrm{~mL})$ was added methyl bromoacetate $(0.18 \mathrm{~mL}, 1.89 \mathrm{mmol}) . \mathrm{K}_{2} \mathrm{CO}_{3}(0.42 \mathrm{~g}$. $3.0 \mathrm{mmol}$ ) and a catalytic amount of KI. and the mixture was heated for $36 \mathrm{~h}$ at reflux. After cooling. the solvent was removed. The residue was partitioned between $\mathrm{H}_{2} \mathrm{O}$ and EtOAc and the organic layer was separated. washed with brine dried over $\mathrm{MgSO}_{4}$. concentrated and purified by column chromatography ( $\mathrm{Hex}: \mathrm{EtOAc}=10: 1$ ) to give the ester $(0.24$ g. $85 \%)$, which was then treated with $\mathrm{CF}_{3} \mathrm{COOH}$ (2 $\mathrm{mL})$ in $\mathrm{CH}_{2} \mathrm{Cl}_{2}(10 \mathrm{~mL})$. The mixture was stirred for $13 \mathrm{~h}$ at room temperature and concentrated to give the amino carbazole 6: 'H NMR (200 MHz, $\mathrm{CDCl}_{\mathfrak{j}}$ ) $\delta 7.25$ (brs. $1 \mathrm{H}$ ). $7.13(\mathrm{~d} . J=8.4 \mathrm{~Hz} .1 \mathrm{H}) .6 .90(\mathrm{~d} J=2.3 \mathrm{~Hz}, 1 \mathrm{H}) .6 .76(\mathrm{dd} . J$ $=8.4 .2 .3 \mathrm{~Hz}, 1 \mathrm{H}) .4 .66(\mathrm{~s} .2 \mathrm{H}) .3 .81(\mathrm{~s} .3 \mathrm{H}) .3 .28(\mathrm{~m}, 1 \mathrm{H})$. $2.99(\mathrm{dd} . J=15.1 .5 .3 \mathrm{~Hz}, 1 \mathrm{H}) .2 .79(\mathrm{~m}, 2 \mathrm{H}) .2 .42(\mathrm{~J}=15.1$. $8.4 \mathrm{~Hz}, 1 \mathrm{H}) .2 .05(\mathrm{~m}, 1 \mathrm{H}) .1 .78(\mathrm{~m}, \mathrm{lH})$.

6-Methoxy-2,3,4,9-tetrahydro- $1 H$-carbazol-3-ylamine (7a). To a solution of the $\mathrm{N}-\mathrm{Cbz}$ tetrahydrocarbazole 4 a (0.50 g. $1.43 \mathrm{mmol}$ ) and ammonium formate $(0.37 \mathrm{~g} .5 .11$ mmol) in EtOH $(50 \mathrm{~mL})$ was added $10 \%-\mathrm{Pd} / \mathrm{C}(125 \mathrm{mg})$. and the mixture was stirred for $24 \mathrm{~h}$. then filtered through a pad of Celite. washed with ethanol. The filtrate was concentrated to give the amino tetrahydrocarbazole $7 \mathbf{a}(0.29$ g. 92\%): 'H NMR (200 MHz, $\left.\mathrm{CDCl}_{3}\right) \delta 7.78$ (brs. $\left.1 \mathrm{H}\right) .7 .14$ $($ d. $J=8.6 \mathrm{~Hz}, 1 \mathrm{H}), 6.91(\mathrm{~d} . J=2.4 \mathrm{~Hz}, 1 \mathrm{H}), 6.76(\mathrm{dd}, J=$ 8.6. $2.4 \mathrm{~Hz}, 1 \mathrm{H}) .3 .85$ (s. $3 \mathrm{H}) .3 .24(\mathrm{~m}, 1 \mathrm{H}) .2 .99$ (dd $J=$ $15.3 .5 .4 \mathrm{~Hz}, \mathrm{lH}), 2.79(\mathrm{~m}, 2 \mathrm{H}), 2.42(J=15.3 .8 .3 \mathrm{~Hz}, 1 \mathrm{H})$. $2.02(\mathrm{~m}, \mathrm{lH}), 1.78(\mathrm{~m}, \mathrm{lH}): \mathrm{MS}(m e) 216\left(\mathrm{M}^{-}, 62\right), 199$ (27). 173 (100). $158(31)$.

(6-Amino-6,7,8,9-tetrahydro-5 $H$-carbazol-3-yl)acetic acid methyl ester (7b). ' $\mathrm{H}$ NMR (200 MHz. $\left.\mathrm{CDCl}_{3}\right) \delta 7.77$ (brs. $1 \mathrm{H}) .7 .14(\mathrm{~d}, J=8.4 \mathrm{~Hz}, 1 \mathrm{H}), 6.91(\mathrm{~d} . J=2.4 \mathrm{~Hz}, 1 \mathrm{H})$. $6.76($ dd $J=8.4 .2 .4 \mathrm{~Hz}, 1 \mathrm{H}) .3 .69$ (s. $2 \mathrm{H}$ ). 3.66 (s. $3 \mathrm{H}$ ). $3.23(\mathrm{~m} .1 \mathrm{H}) .2 .99(\mathrm{dd} J=15.4 .5 .4 \mathrm{~Hz} .1 \mathrm{H}) .2 .79(\mathrm{~m} .2 \mathrm{H})$. $2.42(J=15.4 .8 .3 \mathrm{~Hz}, 1 \mathrm{H}) .2 .02(\mathrm{~m} .1 \mathrm{H}), 1.78(\mathrm{~m} .1 \mathrm{H})$.

6-Amino-6,7,8,9-tetrahydro-5 $H$-carbazole-3-carboxylic acid ethyl ester (7c). ' $\mathrm{H}$ NMR (200 MHz, $\left.\mathrm{CDCl}_{3}\right) \delta 8.21$ (s. $1 \mathrm{H}) .7 .85(\mathrm{dd} . J=8.5,1.6 \mathrm{~Hz}, \mathrm{HH}) .7 .25(\mathrm{~d} . J=8.3 \mathrm{~Hz}, 1 \mathrm{H})$. 4.39 (q. $J=7.4 \mathrm{~Hz}, 2 \mathrm{H}) .3 .31(\mathrm{~m}, 1 \mathrm{H}) .3 .06(\mathrm{dd} . J=15.2 .5 .4$ Hz. 1H). $2.82(\mathrm{~m}, 2 \mathrm{H}), 2.49(J=15.2 .7 .7 \mathrm{~Hz}, 1 \mathrm{H}), 2.05(\mathrm{~m}$. $1 \mathrm{H}) .1 .81(\mathrm{~m} .1 \mathrm{H}) .1 .41(\mathrm{t} J=7.4 \mathrm{~Hz} .3 \mathrm{H})$ : MS (me $) .258$ $\left(\mathrm{M}^{+} .37\right) .215$ (100), $187(35) .170(19) .142$ (13). 115 (11).

6-Fluoro-2,3,4,9-tetrahydro- $H$-carbazol-3-ylamine (7d). ' H NMR (200 MHz. $\left.\mathrm{CDCl}_{j}\right) \delta 8.02$ (br s. $\left.1 \mathrm{H}\right) .7 .17-$ $7.04(\mathrm{~m} .2 \mathrm{H}) .6 .84(\mathrm{~m} .1 \mathrm{H}) .3 .32(\mathrm{~m} . \mathrm{lH}) .2 .96(\mathrm{dd} J=15.0$. $5.0 \mathrm{~Hz}, 1 \mathrm{H}) .2 .41(\mathrm{~m}, \mathrm{lH}) .2 .03(\mathrm{~m}, 1 \mathrm{H}), 1.77(\mathrm{~m}, 1 \mathrm{H}) .1 .50$ (s. 2H): MS (me), $204\left(\mathrm{M}^{-}, 48\right), 186(19), 161(100), 133$ (15).
2,3,4,9-Tetrahydro-1 $\boldsymbol{H}$-carbazol-3-ylamine (7e). ${ }^{1} \mathrm{H}$ NMR $\left(200 \mathrm{MHz} . \mathrm{CDCl}_{2}\right) \delta 7.79$ (br s. $1 \mathrm{H}$ ). 7.45 (dd. $J=7.0$. $2.0 \mathrm{~Hz}, \mathrm{lH}) .7 .25(\mathrm{~m}, 1 \mathrm{H}), 7.19-7.01(\mathrm{~m}, 2 \mathrm{H}) .3 .31(\mathrm{~m}, \mathrm{lH})$ 3.04 (dd $J=15.0 .5 .2 \mathrm{~Hz}, 1 \mathrm{H}), 2.83(\mathrm{~m} .2 \mathrm{H}), 2.42$ (dd. $J=$ $15.0 .8 .2 \mathrm{~Hz}, 1 \mathrm{H}), 2.05(\mathrm{~m}, 1 \mathrm{H}), 1.85(\mathrm{~m}, 1 \mathrm{H})$ : MS $(m e)$. $186\left(\mathrm{M}^{-} .23\right), 168(9), 143(100) .115(20)$.

(R)-\{6-[2-(3-Chloropheny])-2-hydroxyethylamino]-6,7, 8,9-tetrahydro-5H-carbazol-3-yloxy\}acetic acid methyl ester (1a). A solution of $(R)-(+)-3$-Chlorosty rene oxide (30 $\mathrm{mg} .0 .19 \mathrm{mmol}$ ) and the 6 -aminotetrahydrocarbazole 6 (43 mg. $0.16 \mathrm{mmol})$ in $\mathrm{MeOH}(1 \mathrm{~mL})$ was heated for $12 \mathrm{~h}$. After cooling. the mixture was concentrated and the residue was purified with column chromatography $\left(3 \% \mathrm{MeOH} / \mathrm{CH}_{2} \mathrm{Cl}_{2}\right)$ to give the ethanolamine $1 \mathrm{a}$ (38 mg. 56\%): ${ }^{\mathrm{H}} \mathrm{H}$ NMR (200 $\mathrm{MHz}_{2} \mathrm{CDCl}_{2}$ ) $\delta 7.25$ (brs. $1 \mathrm{H}$ ). $7.25-7.23(\mathrm{~m}, 4 \mathrm{H}) .7 .12$ (d. $J$ $=8.4 \mathrm{~Hz}, 1 \mathrm{H}), 6.91(\mathrm{~d} . J=2.3 \mathrm{~Hz}, 1 \mathrm{H}) .6 .77(\mathrm{dd} . J=8.4 .2 .3$ Hz. 1H). 4.71 (m. lH). 4.66 (s. 2H). 3.81 (s. $3 \mathrm{H}) .3 .28$ (m. 1H). $3.15-3.10(\mathrm{~m}, 2 \mathrm{H}), 2.99(\mathrm{dd} J=15.1 .5 .3 \mathrm{~Hz}, 1 \mathrm{H}), 2.79$ (m. 2H) 2.42 (d. $J=15.1 .8 .4 \mathrm{~Hz}, 1 \mathrm{H}), 2.05$ (n. $1 \mathrm{H}), 1.78$ (m. $1 \mathrm{H})$ : HRMS $\left(\mathrm{M}^{+}\right)$calcd for $\mathrm{C}_{23} \mathrm{H}_{25} \mathrm{ClN}_{2} \mathrm{O}_{4} 428.1503$. found 428.1503 .

(R)-1-(3-Chlorophenyl)-2-(6-methoxy-2,3,4,9-tetrahydro1H-carbazol-3-ylamino)ethanol (1b). ${ }^{\mathrm{l}} \mathrm{H}$ NMR $(200 \mathrm{MHz}$. $\left.\mathrm{CDCl}_{3}\right) \delta 7.78$ (brs. $\left.1 \mathrm{H}\right), 7.25-7.22(\mathrm{~m}, 4 \mathrm{H}) .7 .15$ (d. $J=8.5$ $\mathrm{Hz}, 1 \mathrm{H}), 6.91(\mathrm{~d}, J=2.4 \mathrm{~Hz}, 1 \mathrm{H}), 6.76($ dd $J=8.6 .2 .4 \mathrm{~Hz}$. 1H). $4.71(\mathrm{~m} .1 \mathrm{H}) .3 .85(\mathrm{~s} .3 \mathrm{H}) .3 .24(\mathrm{~m} .1 \mathrm{H}) .3 .16-3.12(\mathrm{~m}$. 2H). $2.99(\mathrm{~m}, 1 \mathrm{H}) .2 .79(\mathrm{~m} .2 \mathrm{H}) .2 .42(\mathrm{~m} .1 \mathrm{H}) .2 .02(\mathrm{~m} .1 \mathrm{H})$. $1.79(\mathrm{~m} .1 \mathrm{H})$.

(R)-\{6-[2-Chlorophenyl]-2hydroxyethylamino\}-6,7,8,9tetrahydro- $5 H$-carbazol-3-yl\}acetic acid methyl ester (1c). 'H NMR (200 MHz. $\left.\mathrm{CDCl}_{2}\right) \delta 7.78$ (brs. 1H). 7.41$7.04(\mathrm{~m} .7 \mathrm{H}), 4.73(\mathrm{~m} .1 \mathrm{H}), 3.69$ (s. $2 \mathrm{H}) .3 .67$ (s. 3H). 3.15$2.48(\mathrm{~m}, 9 \mathrm{H}), 2.12(\mathrm{~m}, 2 \mathrm{H}), 1.86(\mathrm{~m}, 1 \mathrm{H})$ : MS $(\mathrm{me}), 412$ $\left(\mathrm{M}^{-}, 13\right) .349$ (11). 271 (65), 242 (47). $215(57), 141$ (100): HRMS $\left(\mathrm{M}^{-}\right)$calcd for $\mathrm{C}_{23} \mathrm{H}_{25} \mathrm{ClN}_{2} \mathrm{O}_{3}$ 412.1554. found 412.1561 .

(R)-6-[2-(3-Chloropheny])-2-hydroxyethylamino]-6,7, 8,9-tetrahydro-5 $H$-carbazole-3-carboxylic acid ethyl ester (1d). ${ }^{1} \mathrm{H}$ NMR (200 MHz. CDCl $\left.{ }_{2}\right) \delta 8.18$ (brs. 2H). 7.84 (dd, $J=8.4 .1 .4 \mathrm{~Hz}, 1 \mathrm{H}), 7.27$ (s. $1 \mathrm{H}) .7 .25-7.23(\mathrm{~m}$. $4 \mathrm{H}), 4.71(\mathrm{~m}, 1 \mathrm{H}), 4.38(\mathrm{q} . J=7.2 \mathrm{~Hz}, 2 \mathrm{H}), 3.15-3.11(\mathrm{~m}$. $3 \mathrm{H}), 3.09-2.52(\mathrm{~m}, 6 \mathrm{H}), 2.15(\mathrm{~m}, 1 \mathrm{H}) .1 .86(\mathrm{~m} .1 \mathrm{H}) .1 .41(\mathrm{t}$. $J=7.2 \mathrm{~Hz}, 3 \mathrm{H})$ : MS $(m e), 412\left(\mathrm{M}^{+}, 6\right), 271(65), 258(18)$, 242 (19). 215 (100). 187 (33). $168(31) .77(41)$.

(R)-1-(3-Chlorophenyl)-2-(6-fluoro-2,3,4,9-tetrahydro1H-carbazol-3-ylamino)ethanol (1e). ${ }^{1} \mathrm{H}$ NMR $(200 \mathrm{MHz}$. $\left.\mathrm{CDCl}_{3}\right) \delta 7.82$ (brs, $\left.1 \mathrm{H}\right), 7.31-6.79(\mathrm{~m}, 8 \mathrm{H}), 4.20(\mathrm{~m}, \mathrm{lH})$. $4.00(\mathrm{~m}, 2 \mathrm{H}), 3.40(\mathrm{~m}, 3 \mathrm{H}), 3.18-2.80(\mathrm{~m}, 6 \mathrm{H}), 2.62(\mathrm{~m}, 1 \mathrm{H})$. $2.18(\mathrm{~m}, 1 \mathrm{H}), 1.97(\mathrm{~m}, 1 \mathrm{H})$ : MS (me). $354\left(\mathrm{M}^{-}, 29\right), 217$ (13). $188(22) .161(100)$.

(R)-1-(3-Chlorophenyl)-2-(2,3,4,9-tetrahydro-1 $H$-carbazol-3-ylamino)ethanol (1f). ${ }^{1} \mathrm{H}$ NMR $\left(200 \mathrm{MHz}^{\circ} \mathrm{CDCl}_{3}\right) \delta$ 7.74 (brs. $1 \mathrm{H}$ ). $7.46-7.41$ (m. $2 \mathrm{H}) .7 .33-7.26(\mathrm{~m} .4 \mathrm{H}) .7 .17-$ $7.05(\mathrm{~m} .2 \mathrm{H}), 4.69(\mathrm{~m}, 1 \mathrm{H}) .3 .20-3.03(\mathrm{~m}, 3 \mathrm{H}), 2.85-2.73$ (m. 3H). 2.62-2.51 (m, 3H). $2.16(\mathrm{~m}, 1 \mathrm{H}) .1 .87(\mathrm{~m} .1 \mathrm{H})$ : MS (me). $342\left(\mathrm{M}^{-}+2.4\right) .340(12) .199(88) .170(59), 143$ $(100)$ 
(R)-6-[2-(3-Chlorophenyl)-2-hydroxyethylamino]-6,7, 8,9-tetrahydro-5H-carbazol-3-ol (1g). ${ }^{1} \mathrm{H}$ NMR (200 $\left.\mathrm{MHz}, \mathrm{CDCl}_{3}\right) \delta 7.73$ (brs. $1 \mathrm{H}$ ). $7.41-7.03(\mathrm{~m} .4 \mathrm{H}) .7 .04(\mathrm{~d} J$ $=8.4 \mathrm{~Hz} .1 \mathrm{H}) .6 .73(\mathrm{~d} . J=2.4 \mathrm{~Hz} .1 \mathrm{H}) .6 .55(\mathrm{dd} J=8.4 .2 .4$ Hz. $1 \mathrm{H}) .4 .70(\mathrm{~m}, 1 \mathrm{H}) .3 .24(\mathrm{~m}, 1 \mathrm{H}) .3 .15-3.12(\mathrm{~m}, 2 \mathrm{H})$. $2.90-2.78(\mathrm{~m} .2 \mathrm{H}) .2 .32(\mathrm{~m} .1 \mathrm{H}) .2 .0 \mathrm{l}(\mathrm{m} .1 \mathrm{H}) .1 .76(\mathrm{~m} .1 \mathrm{H})$.

(R)-(\{6-[2-(3-Chlorophenyl)-2-hydroxyethylamino]-6, 7,8,9-tetrahydro-5 $H$-carbazole-3-carbonyl!amino)acetic acid ethyl ester (1j). A solution of the carboxylic acid 4 $(0.36 \mathrm{~g} .1 \mathrm{mmol})$. glycine ethyl ester hydrochloride $(0.17 \mathrm{~g}$. $1.2 \mathrm{mmol}$ ). 1-(3-dimethy laminopropy l)-3-ethy lcarbodiimide hydrochloride $(0.28 \mathrm{~g} .1 .5 \mathrm{mmol})$. 1-hydroxy benzotriazole $(0.16 \mathrm{~g} .1 .2 \mathrm{mmol})$, and triethylamine $(0.78 \mathrm{~mL} .2 \mathrm{mmol})$ in DMF $(5 \mathrm{~mL})$ was stirred at room temperature for $5 \mathrm{~h}$. Ethyl acetate was added. and the mixture was washed with sat. $\mathrm{NaHCO}_{3}$ solution. water. and brine. The organic solution was dried over $\mathrm{MgSO}_{4}$. concentrated and purified with column chromatograply ( $\mathrm{Hex}: \mathrm{EtOAc}=3: 1$ ) to give the amide $9 \mathrm{c}(0.29 \mathrm{~g} .66 \%)$ : ${ }^{l} \mathrm{H}$ NMR $\left(200 \mathrm{MHz} . \mathrm{CDCl}_{3}\right) \delta 8.18$ (brs. $1 \mathrm{H}$ ). 8.09 (brs. 1H). 7.84 (dd $J=8.5 .1 .6 \mathrm{~Hz} .1 \mathrm{H}$ ). 7.24 (d. $J=8.5, \mathrm{~Hz}, 1 \mathrm{H}$ ). $7.34-7.33(\mathrm{~m}, 5 \mathrm{H}), 5.12$ (s. $2 \mathrm{H}) .4 .93$ (br d. $1 \mathrm{H}) .4 .24(\mathrm{q} . J=7.2 \mathrm{~Hz}, 2 \mathrm{H}), 4.16(\mathrm{~m}, \mathrm{lH}) .3 .12(\mathrm{dd} . J=$ 15.4. $5.4 \mathrm{~Hz}, \mathrm{lH}), 2.81(\mathrm{~m}, 2 \mathrm{H}), 2.64(\mathrm{dd} . J=15.4 .6 .7 \mathrm{~Hz}$. lH). $1.95(\mathrm{~m}, 2 \mathrm{H}) .1 .23(\mathrm{t} . J=7.2 \mathrm{~Hz}, 3 \mathrm{H})$. The glycine amide $9 \mathrm{c}$ was transformed to the arylethanolamine $1 \mathrm{j}$ by following the procedure as described in the sy'nthesis of $7 \mathbf{a}$ and 1a. ${ }^{\circ} \mathrm{H} \mathrm{NMR}\left(200 \mathrm{MHz}, \mathrm{CDCl}_{3}\right) \delta 8.30$ (brs. $\left.\mathrm{lH}\right) .7 .89$ (br s. 1H) 7.54 (d. $J=9.2 \mathrm{~Hz} .1 \mathrm{H}) .7 .40(\mathrm{~m} .1 \mathrm{H}) .7 .30-7.19$ (m. $4 \mathrm{H}) .6 .80$ (br s. $1 \mathrm{H}) .4 .74$ (m. 1H). 4.25 (br s. $2 \mathrm{H}$ ). $3.18-$ $2.90(\mathrm{~m} .4 \mathrm{H}) .2 .72(\mathrm{~m} .2 \mathrm{H}) .2 .51(\mathrm{~m} .1 \mathrm{H}) .2 .11(\mathrm{~m} .1 \mathrm{H})$. $21.91(\mathrm{~m} .1 \mathrm{H}) .1 .23(\mathrm{t} . J=7.2 \mathrm{~Hz} .3 \mathrm{H})$ : HRMS $\left(\mathrm{M}^{-}\right)$calcd for $\mathrm{C}_{35} \mathrm{H}_{28} \mathrm{ClN}_{3} \mathrm{O}_{4} 469.1768$. found 469.1764 .

(R)-6-[2-(3-Chlorophenyl)-2-hydroxyethylamino]-6,7, 8,9-tetrahydro-5 $H$-carbazole-3-carboxylic acid phenylamide (1i). 'H NMR (200 MHz, CD $\left.{ }_{3} \mathrm{OD}\right) \delta 7.99$ (brs. 1H). 7.61-7.56 (m. 3H). $7.36(\mathrm{~s} .1 \mathrm{H}) .7 .28-7.19(\mathrm{~m} .6 \mathrm{H}) .7 .03(\mathrm{~m}$. $\mathrm{lH}) .4 .72(\mathrm{~m}, \mathrm{lH}) .3 .57(\mathrm{~m}, \mathrm{lH}) .3 .46(\mathrm{~m}, \mathrm{lH}) .3 .08(\mathrm{~m} .3 \mathrm{H})$. $2.91-2.77(\mathrm{~m} .5 \mathrm{H}) .2 .50(\mathrm{~m} .1 \mathrm{H}) .2 .11(\mathrm{~m} .1 \mathrm{H}) .1 .80(\mathrm{~m} .1 \mathrm{H})$. HRMS $\left(\mathrm{M}^{-}\right)$calcd for $\mathrm{C}_{37} \mathrm{H}_{26} \mathrm{ClN}_{3} \mathrm{O}_{2}$ 459.1714, found 459.1711 .

(R)-6-[2-(3-Chlorophenyl)-2-hydroxyethylamino]-6,7, 8,9-tetrahydro-5 $\mathrm{H}$-carbazole-3-carboxylic acid amide (1k). ${ }^{1} \mathrm{H}$ NMR (200 MHz, CD $\left.{ }_{3} \mathrm{OD}\right) \delta 8.08(\mathrm{~d} . J=2.0 \mathrm{~Hz}$. $\mathrm{lH}), \mathrm{lH}) .7 .71(\mathrm{~m} . \mathrm{lH}) .7 .52$ (s. $1 \mathrm{H}) .7 .42-7.33(\mathrm{~m} .4 \mathrm{H})$. $4.85(\mathrm{~m}, \mathrm{lH}) .3 .38-2.93(\mathrm{~m} .10 \mathrm{H}) .2 .64(\mathrm{~m} .1 \mathrm{H}) .2 .28(\mathrm{~m}$. $\mathrm{lH}) .2 .08(\mathrm{~m}, \mathrm{HH}) .1 .96(\mathrm{~m} .1 \mathrm{H})$ : HRMS $\left(\mathrm{M}^{-}\right)$calcd for $\mathrm{C}_{23} \mathrm{H}_{2} \mathrm{ClN}_{3} \mathrm{O}_{2} 383.1401$, found 383.1400 .

(R)-Pyrrolidine-1-carboxylic acid \{6-[2-(3-chloropheny)-2-hydroxyethylamino]-6,7,8,9-tetrahydro-5 $H$-carbazol3-yl\}amide (1m). To a solution of DMF $(0.32 \mathrm{~mL}, 4.1$ mmol) in benzene $(3 \mathrm{~mL})$ was added thionyl chloride $(0.32$ $\mathrm{mL} .4 .4 \mathrm{mmol}$ ) at $0^{\circ} \mathrm{C}$ and the solution was stirred for 10 min at room temperature. After cooling to $-5{ }^{\circ} \mathrm{C}$. the tetrahydrocarbazole carboxylic acid $4(1.0 \mathrm{~g} .2 .75 \mathrm{~mm} o \mathrm{l})$. pyridine $(0.76 \mathrm{~mL} .9 .3 \mathrm{mmol})$, and sodium azide $(0.61 \mathrm{~g} .9 .3$ mmol) were added to the solution and the resulting suspension was stirred for $10 \mathrm{~min}$. followed by additional stirring for $2 \mathrm{~h}$ at room temperature. The reaction mixture was poured into water. extracted with EtOAc and the organic layer was washed with brine dried over $\mathrm{MgSO}_{4}$, and concentrated. The residue was dissolved in toluene $(30 \mathrm{~mL})$. heated for $10 \mathrm{~min}$. and concentrated to give the isocyanate 11. which was used for the next reaction without further purification. To a solution of isocyanate $(0.2 \mathrm{~g} .0 .55 \mathrm{mmol})$ in THF ( $3 \mathrm{~mL}$ ) was added pyrrolidine $(0.23 \mathrm{~mL} .2 .77 \mathrm{mmol})$ and the mixture was heated for $12 \mathrm{~h}$. After cooling. the mixture was partitioned between $\mathrm{H}_{2} \mathrm{O}$ and EtOAc. and the organic layer was separated washed with brine. dried. concentrated and purified with colunun chromatograply (Hex: $\mathrm{EtOAc}=5: 1)$ to give $\{6-[$ (pyrrolidine-1-carbonyl)aminol-2.3.4.9-tetrahydro-1 $H$-carbazol-3-yl $\}$ carbamic acid benzyll ester $12 \mathrm{~b}(0.11 \mathrm{~g} .46 \%)$ : 'H NMR (200 MHz. CDCl $\left.\mathrm{C}_{3}\right)$ $\delta 8.02$ (brs. $1 \mathrm{H}) .7 .40-7.35(\mathrm{~m} .6 \mathrm{H}) .7 .12(\mathrm{~d} . J=8.4 \mathrm{~Hz} .1 \mathrm{H})$. 7.00 (dd. $J=10.4 .1 .6 \mathrm{~Hz}, 1 \mathrm{H}$ ), 6.13 (s. $1 \mathrm{H}$ ). 5.11 (s. $2 \mathrm{H}$ ). $4.12(\mathrm{~m}, 1 \mathrm{H}), 3.45(\mathrm{~m} .4 \mathrm{H}), 2.89(\mathrm{dd} . J=15.6 .5 .4 \mathrm{~Hz} .1 \mathrm{H})$. $2.68(\mathrm{~m}, 2 \mathrm{H}), 2.38(\mathrm{dd}, J=15.6,7.2 \mathrm{~Hz}, 1 \mathrm{H}), 1.95(\mathrm{~m}, 6 \mathrm{H})$. The benzyl ester $12 \mathrm{~b}$ was transformed to the arylethanolamine $1 \mathrm{~m}$ by following the procedure as described in the synthesis of 7a and 1a: ${ }^{1} \mathrm{H}$ NMR (200 MHz. DMSO-d 6 ) $\delta$ 8.31 (brs. 1H). 7.41-7.26 (m. 5H). 7.09 (m. 1H). $6.96(\mathrm{~m}$. 1H), 6.40 (s. $1 \mathrm{H}), 4.81(\mathrm{~m}, 1 \mathrm{H}) .3 .35(\mathrm{~m}, 4 \mathrm{H}), 3.19(\mathrm{~m}, \mathrm{lH})$, $2.89-2.61$ (m. 3H). 2.25 (dd $J=15.4 .6 .6 \mathrm{~Hz}, 1 \mathrm{H}) .1 .92(\mathrm{~m}$. 1H). $1.79(\mathrm{~m} .4 \mathrm{H}) .1 .67(\mathrm{~m} . \mathrm{lH})$.

(R)-N-\{6-[2-(3-Chlorophenyl)-2-hydroxyethylamino]6,7,8,9-tetrahydro-5 $\mathrm{H}$-carbazol-3-yl\}methansulfonamide (1n). ${ }^{1} \mathrm{H}$ NMR $\left(300 \mathrm{MHz} . \mathrm{CD}_{3} \mathrm{OD}\right) \delta 7.47$ (brs. $\left.1 \mathrm{H}\right) .7 .35-$ $7.28(\mathrm{~m}, 4 \mathrm{H}) .7 .22(\mathrm{~d}, J=8.4 \mathrm{~Hz} .1 \mathrm{H}) .6 .96(\mathrm{~d}, J=1.1 \mathrm{~Hz}$. 1H). 4.85 (m. 1H). $3.28(\mathrm{~m} .1 \mathrm{H}) .2 .84$ (s. 3H). 2.83-2.61 (m. $5 \mathrm{H}) .2 .56(\mathrm{~m} .1 \mathrm{H}) .2 .18(\mathrm{~m} .1 \mathrm{H}) .1 .92(\mathrm{~m} .1 \mathrm{H})$ : HRMS (M $\left.{ }^{-}\right)$ calcd for $\mathrm{C}_{21} \mathrm{H}_{2} \mathrm{ClN}_{3} \mathrm{O}_{3} \mathrm{~S} 433.1226$, found 433.1225 .

(R)-3-\{6-[2-(3-Chlorophenyl)-2-hydroxyethylamino]6,7,8,9-tetrahydro- $5 H$-carbazol-3-yl propionic acid methyl ester (10). A mixture of 4 f $(0.21 \mathrm{~g} .0 .53 \mathrm{mmol})$. methyl acrylate $(0.1 \mathrm{~mL}, 0.16 \mathrm{mmol})$, palladium acetate $(20$ $\mathrm{mg}$ ). sodium acetate ( $93 \mathrm{mg} .1 .1 \mathrm{mmol}$ ). and $N, N$-dimethylglycine $(20 \mathrm{mg})$ in $N$-methylpyrrolidinone $(5 \mathrm{~mL})$ in pressure tube was heated for $12 \mathrm{~h}$ at $135^{\circ} \mathrm{C}$. and partitioned between saturated $\mathrm{NH}_{4} \mathrm{Cl}$ and ethyl acetate. The organic layer was dried with $\mathrm{MgSO}_{4}$. concentrated. and purified with column chromatography to give the tetrahydrocarbazole acrylate $14(0.15$ g. $72 \%)$ : ${ }^{1} \mathrm{H}$ NMR (200 MHz. $\left.\mathrm{CDCl}_{3}\right) \delta$ 8.15 (brs. $1 \mathrm{H}) .7 .80(\mathrm{~d} . J=16.0 \mathrm{~Hz}, 1 \mathrm{H}) .7 .55(1,1 \mathrm{H}) .7 .37-$ 7.21 (m. $7 \mathrm{H}$ ). 6.39 (d. $J=16.0 \mathrm{~Hz}, 1 \mathrm{H}$ ). 5.11 (s. 2H). 5.00 (brs. 1H). 4.14 (m. 1H). 3.80 (s. 3H). 3.09 (dd. $J=15.4 .5 .2$ Hz, $1 \mathrm{H}), 2.80(\mathrm{~m}, 2 \mathrm{H}), 2.64$ (dd. $J=15.4 .6 .7 \mathrm{~Hz}, 1 \mathrm{H}), 2.04$ (m. 2H): MS (me). 404 (M- 2), 296 (1), 252 (3). 91 (100). The acrylate 14 was transformd to the ary lethanolamine 10 by following the procedure as described in the sy'nthesis of 7a and 1a. For the compound 10: ${ }^{1} \mathrm{H}$ NMR $(200 \mathrm{MHz}$. $\mathrm{CDCl}_{3}$ ) $\delta 7.81$ (s. $\left.1 \mathrm{H}\right) .7 .40$ (s. $\left.1 \mathrm{H}\right) .7 .25-7.23(\mathrm{~m} .4 \mathrm{H}) .7 .16$ $(\mathrm{d} . J=8.2 \mathrm{~Hz}, \mathrm{lH}) .6 .95(\mathrm{dd} J=8.2 .1 .6 \mathrm{~Hz}, 1 \mathrm{H}) .4 .73(\mathrm{~m}$. 1H), 3.66 (s. $3 \mathrm{H}), 3.15-2.49(\mathrm{~m}, 13 \mathrm{H}), 2.10(\mathrm{~m} . \mathrm{lH}), 1.85$ (m. lH): MS (me). $426\left(\mathrm{M}^{+}, 14\right), 285(100) .256(67), 229$ (74). 156 (48): HRMS $\left(M^{+}\right)$calcd for $\mathrm{C}_{24} \mathrm{H}_{27} \mathrm{ClN}_{2} \mathrm{O}_{3}$ 
426.1710. found 426.1708 .

Measurement of $\beta_{3}$-adrenoceptor binding affinity. To determine the binding affinity of $\mathbf{1} \mathbf{a}-\mathbf{0}$ on $\beta_{3}$-adrenoceptor. RB-HBETA3 membrane was incubated with [ $\left.{ }^{125} \mathrm{I}\right]$-iodocyanopindolol (1.4 nM. $2000 \mathrm{Ci} / \mathrm{mmol})$ and unlabeled ligand for $10 \mathrm{~min}$ at $37^{\circ} \mathrm{C}$. Propranolol ( $1 \mathrm{mM}$ ) was used to define non-specific binding. Incubation mixture was filtered over glass fiber (Wallac 140-521). washed and measured for radioactivity.

Acknowledgments. This work was supported by Ministry of Science and Technology of Korea and Bioneer Corporation.

\section{References}

1. (a) Lands. A. M.: Anold. A.: McAulift.. J. P: Luduena. F. P.: Brown. T. G. Jr. Nature 1967. 214. 597. (b) Strosberg. A. D. Ann. Rew Pharmacol. Toricol. 1997, 37. 421.

2. (a) Arch. T. G. S. Proc. Nutrition Soc. 1989, 18. 215. (b) Emorine. L. J: Marullo. S.: Briend-Sutren. M.-M: Patev. G.: Tate. K.: Delavier-Klutchko, C.: Strosberg. A. D. Science 1989, 245. 1118. (c) Tan. S.: Curtis-Prior. P. B. Int. J. Obesity 1983. 7.409.

3. Lafonate. M.: Berlan. M. J. Lipid Res. 1993. 34. 1057.

4. (a) Weyer. C.: Gautier. J. F.: Danforth. E.. Jr. Diabetes Metat. 1999. 25. 11. (b) Souza. J. C.: Burkey. B. F. Cur: Pharm. Des. $2001,7,143$. (c) Weber. A. E. Amm Rep. Ned (Chem. 1998. 33. 193.

5. (a) Cantello, B. C. C.: Smith. S. A. Drugs Futhe 1991. 16. 797. (b) Sher. P. M.: Fisher. L. G.: Skwish. S.: Michel. I. M.: Seiler. S. M.: Washburn. W. N.: Dickinson. K. E. J. Med. Chem. Res. 1997. 7. 109 .

6. Bloom, J. D.; Dutia. M. D.; Johnson. B. D.: Wissner. A.: Bunns,
M. G.: Largis, E. E.: Dolan, J. A.: Claus. T. H. J. Hed. Chem. 1992.35.3081.

7. Harada. H.: Hirokawa. Y:: Suzuki. K: Hiyama. Y: One. M: Kawashima. H.: Yoshida. N.: Funtani. Y.: Kato. S. Bioong. Med. Chem. Lett. 2003, 13. 1301

8. (a) Cecchi, R.: Croci, T.; Boigegrain. R.; Boveri. S.; Baroni. M:; Boceardi. G.: Guimbard. J. P. Guzzi. U. Ew d. Med Chem. 1994 29. 259. (b) Badone. D.: Guzzi. U. Bioorg Med. Chem. Lett. 1994. t. 1921

9. Cooke. J. W. B.: Glower. B. N.: Lawrence. R. M.: Sharp. M. T.: Timoschenko. M. F. WO 0266418, April 15. 2001.

10. Yanai. M.: Kawamura K.: Ueno. M.: Hiramoto, S.; Katsuyama. K: Fuchizawa, S.: Takahashi. T. 220th ACS Natl. Meet. (Washington DC). Abst. MEDI 303.2000.

11. (a) Hieble. J. P.: Bondinell. W. E.: Ruffolo. R. R.. Jr. J. Med. Chent 1995. 38. 3415. (b) Kordik. C. P.: Reitz. A. B. J. Med. Chem 1999, 12,181 .

12. (a) Kang. S. K.: Ha, J. D.; Cheon. H.-G. Choi. J.-K: Hong. C. S. Yum. E. K. Bull. Korean Chem. Soc. 2003. 24. 1381. (b) Ok, H. O.: Reigle. L. B.: Candelore. M. A.: Colwell. L. F.: Deng. L.: Feeney. W. P. F.: Forrest. M. J.: Hom. G. J: Macintyre. D. E.: Strader. C. D.: Tota. L.: Wang. M. T.: Wyvratt. M. T.: Fisher. M. H. Weber, A. E. Bioorg. Hed. Chem. Lett. 2000. 10, 1531.

13. (a) Rogers. C. U.: Corson, B. B. J. Am. Chem Soc. 1947,69. 2911. (b) Edwards, J. P.: West. S. J.; Pooley, C. L. F.: Marschke. K. B.: Farmer. L. T.: Tones. T. K. Bioorg. Med Chem. Lett. 1998. 8. 745 .

14. Fisher. M. H.: Amend. A. M.: Bach. T. J.: Baker. T. M.: Brady. E. J.: Candelore. M. R.; Carroll. D.: Cascieri, M. A.: Chiu, S.-H. L.; Deng. L.; Forrest. M. J.; Hegarty-Friscino. B.; Guan, X.-M.: Hom. G. J.: Hutchins, J. E.: Kelly, L. J:; Mathvik, R. J.: Metzger. J. M: Miller. R. R.: Ok, H. O.; Parmee. E. R.: Saperstein. R.; Strader, C. D.: Stearns. R. A.: Thompson. G. M.: Tota. L.: Vicario. P. P: Weber. A. E.: Woods. J. W: Wyvratt. M. I.: Zatianl. P. T: MacIntyre. D. E. J. Clin. Inest. 1998. 101. 2387.

15. Yang. S. D.: Rhee, S. D. unpulished results 